ON THE SUPERFICIAL VISCIDITY OF LIQUIDS. Translated for "ScIFnce" from the French of J. Plaleau, By the Marchoness Clara lanza.

In the year 1638 Descartes affirmed that the surface of water presented a resisting tendency as though it were covered with a thin pelicle. Several other learned men have asserted the same fact and sought to verify it by various experiments. Some limited their researches to water alone; others maintained that the tests were applicable to all liquids. In my own observations I hate described experiments and facts which, in my opinion, at once remove all doubt as to the reality of a peculiar resisting force manifested by the surface of water, solutions, etc., and I have attributed this resistance to a characteristic viscidity or glutinous matter pertaining exclusively to the outer coating of these liquids. Nevertheless, I have demonstrated that certain other Huids are totally exempt from this peculiarity, and I hope I have fully established the fact, heretofore, that in several among them, such as alcohol, spirits of turpentine, sulphuric ether, etc., the invisible patticles of the outce layer offer, on the contritry, less resistance in regillol to relative displacement than those within the mass.

l'ermit me to recall the tacts of which my principal experiments consist. A magnetized needle is place(f upon a pivot in the centre of a glass cylinder; the liquid to be tested is then poured into the vessel-just enough to come in contact with the needle; the latter is then turned to a meridian of about $90^{\prime}$, then in a tell moments is lett to itselt, and the time which it takes to travel over a determined angle must be correctly ascertitined. In $m y$ experiments the angle was 85 . . More liquid must then be introduced into the cylinder so that the necdle is completely covered, the liquid rising at least two-thirds of an inch above it. The needle is then again turned to a meridian of 90 , and one must remark the time taken to describe the preceding angle. Now, for example, when the liquid is distilled Water, my necdle took precisely twice as long when upon the surface as when beneath it, notwithstanding thit in the first catse the under surface of the needle alone came in contact with the wated, while in the latter it wists completely immersed. When the liguid emplojed wiss alcoloul or terpentine the time required by the meedle, when upon the surtilce, was less by hall than when beneith it.

I must add that in those liquids on whose surface the magnet moves more slowly tham when beneath it, the eritire outer coating moves also, although somewhat less rapidly.

Two-liquids, one a solution of albumen and the other of a saponaceous consisteuc ${ }^{\prime}$, have exhibited superficial viscidity in an extremely forcible manner. After having moved with the utmost slowness, the needle stopped at an angle of $35^{\circ}$ on the surface of the tormer. It did not move at all upon the latter liquid.

I omit purposely the various details relative to those experiments, as well as other facts belonging to the subject in question. I shall mention tir:m furtuer on as the reasons present themselves, and at this tune merely contine myself to the special object of these remarks, tnat is to say, the cause and nature of these phenomena.

In a notice published in $1870, M$. Luvini expressed doubt in regard to the superficial viscidity of liquid matter'. He presumes that the eflects I ingself have observed ale due to some alteration in the vuter surface caused by the contact of the liquid with the air, or elsc by particles of dust tloating about.

In 1872 M. Marangoni published a paper," in which he seeks to prove that the viscidity upon the outer portion of the liquid is identical with that which is beneath the surface. According to him, in such liquids as water, for instance, which does not pruduce butsiles, 'Alcune sperienze considerazioni inturno all' addisione brasolidie liguidi. Turin, 1870 . the resistance is increased by a capillary action exercised by the glass upon the needle; while, when liquids which bubble easily are used, the resistance springs from a thin cuticle in coating of a nature pecultar to the liquid itself.

I replied to both these articles ${ }^{3}$; but M. Mlarangoni attacked me again last year'. In his second work he substitutes, for some unknown reason, particles of dirt for the word cuticle. When speaking of the saponaceous solution, he states that the carbonic acid in the air decomposes the soap and produces an alkaline carbonate which removes the falty acids and forms a kind of emulsion upon the surtace. As to the solutions of albumen he thinks probably that the coating of dust is produced by the evaporation of the watter.

He does not positively deny that the surface of liquids camnot possess a visciclity of its own apart from that "hich is in the mass; but he is persuaded that the influence of the viscidity peculiar to the surface is very small indeed when compared with. that which effects the tinal results. The folluwing is the substance of his theory:

II'e all know that it we place upon any liciuid a drop of another pissessing less external elasticity. the drop will spread itself in at thin coating upon the surlace of the former. Conseguently, when a liguid is covered with at lityer of dirt. We mate reasonably atcmit that this lajer possesses an elastic furce much inferior to that which belong's to the pure, iresh surface of the underlying liquicl. Now proper experiments show us, tirst of ali, that the tension of this coating is effectively much less forcible than that of the liquid beneath; secondly, that if the coating becomes sufficiently thick, the elasticity disappears enticely, or very nearly; thirdly, that in any saponaceous solution the film cian be accumulated upon certain portions of the surface and re noved upon others.

When a bubble is blulin trom one of these liçuids the lijer of dirt extends in both sides of it and thus prevents il.s bieaking. Liquids such as alcohol, ether, turpentine, etc., cannot, owing to the slight elastic force they possess, be covered with a coating of cirt, and for this reasun they are unable to produce bubbles.

The retarded movement of the needle upon the surface of the liquid doe's nut arise from any viscidlity of the outer lajer, for, in the sipronitceuts soluthoin at leatst, this conating

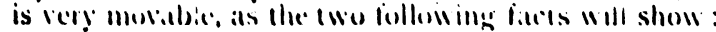

In ihe liest place, when a large soap bublisle is blown. reflecting various colosis, the sightest breath of air will caluse it ow whit ratpidly backwards and torwards. In the second place, if a certain amount of soa, s-surls be put into a horizuntal brass tube sutficiently large for the purpose, and a magnet be placed inside upon a pivot, directed tuward the magnetic meridian, and then left to oscillate at will, sou will perceite that the vibrations are very neariy as raphd as when the magnet moves freely in the air, notwithstanding the fact that it has to worcome the resistance offered by the two outer coatings of the liquad.

W'hen a coating of dirt exists, the sonewhat retarded motion of the magnet upon the surface, together with the rutating movement of the entire mass, can be explanned in the fulluwing manner: The naarnet itselt tends to reinove the dirt which is behınd it and accumulate it all in irunt: this produces an excess of elasticity along the posterior contour. directly oppósed to the natural motion. and at the same time a cimmutive expansive force along the anterior contour. Furthermore, behind each half of the magnet, the superfluity of expansite furce on the fresh surtace draws together the edges of that portion which is already freed from dirt as though to close the rent, and, at the same time, as in each of the anterior parts, the portions far removed from the ed!ge of the magnet possess a weaker expansive force than those nearer to it; the former attract the latter and thus determine the rotation of the enture mass.

3 Reponse aux objections de M. Marangoni contre le principe de 
If the outer layer of the liquid should resist the movement of the magnet from any viscosity of its own, it would pucker percentibly: moreover, viscous bodies propagate motion with difficulty from any distance.

The conting of dirt imitates closely an elastic body, inasmuch as it tonds to return to its primitive state when broken: however, it substilutes, in place of superticial isicrsity, superfaicul elariticity.

In regard to those liquicls of strongr expansive force which do not produce bubbles, such as water. the greater p rtion of briny solutions, etc. liquids upon whose surface a layer of dirt cannot easily be attested, the retarcled movement of the marnet upon the exterior is hardly due to the changres which occur in the catitits of the meniscus, terminating the mannet at each end, partly, also, to the beginning of a laver of dirt. M. IIagen havinir discovered that the surface of water undergoes moditications by exposing the liquid to the air. But the principal cause mov reasonably be sail to be the fact which $M$. Van der Mengrburache has so well described, namely. that when the surtace of any liquid is ausmented, or in other words, when any rliffusion of the pure exterior takes place, a sudden cooling. followed by an increased tension. ensues, and, reciprocally, a waimth and decrease of tension correspond to any diminution or contraction of the surface.

This then is the main substance of the theory proposed by .M. Marangoni in corrpensation for mine. Let us endeatvor to examine it. First of all, it would seem, according to his cloctrine, that it is merely necessary to add to any liquid of strong expmsive force which dues not bubble, a drop of another licyud of weak tension in order to produce larese bubbles from the former. Now if a drop of elive oil or spirits of turpentine be placed upon distilled watter, the liquid will rebel strongly against the formation of bubbles. Should the water be covered with a thin coating of either of the above mentioned liquids, you will find that it bursts in the bowl of the pipe before you have even commene-d to blow the bubble. We must adnit therefore, in the first plice, that the supposed conting of dirt must hate close connection with the liquid beneath it. The author also assierns an additional and indispensible cause for the produc'ion of bubbles which he describes as the suterficial clasticity. or in other words, the facility with which the dirt spreads itself over the liquid, so that the latter is always covered. Nothing however, goes to show us that a thin coiting of olive oil or turpentine does not possess the same clasticity.

The author, in tact, describes wo circumstances in which foreign substances produce a coating upon distilled water which is more or less effectual. First of all, if the pollen of flowers is spread upon the surface and air blown from above within an hour or two, the little apertures formed will remain for a long time; bat the liquid refuses to torm bubbles when blown from a pipe or tube. In the second place, they can be produced, nevertheless, by means of pure distilled water, if the tube is partially filled with small particles of camphor. The diameter of these bubbles may reach an inch and more. But we can readily see that these facts are only the begrinning of success. However, they are in no wise opposed to the thenry of superficial viscidity, since in both cases the outer layer of the water undergoes modifications.

According to the author, the superficial elasticity is estimated by the difference which exists between the tension of the pure surface and that of the dirty surface, and he determines this by means of a small apparatus which he calls a capillary balance. In his opinion, as we have alrealy seen, when a bubble is blown the coating of dirt prevents its being broken. In his statement he gives no reason for this but in a preceding work he explains himself clearly on this point. He silys that if the coating of dirt should become disunited, the excess of tension ufon the under layer, or in other words, the superficial elase ticity, would instantly close the aperture. Ilence the facility for the formation of bubbles, or as the author calls it, the pompholygenic power, should decrease with the superficial elasticity. Now M. Marangoni is led to the conclusion that all causes which tend to diminish this elasticity without removing the dirt, render the development of bubble's much easier. Further on, he returns to this proposition and says that "all those conditions which diminish this elasticity to the advantage of the plasticity increase the pompholygenic force." If we examine closely his ideas, we can understand that an increase of plasticity favors consiclerably the generation of bubbles : but how is it possible that a diminution of elasticity can lead to the same result?

Let us return to the first of the two facts quoted above. The author finds, by means of his canillary bolance, that the superfine elasticity of the distilled water, covered with pollen, mav become doubly as great as that found in the saponaceous solution. Now, inasmuch as the latter produces large bubbles while the former gives none at all, it is necessary, according to .I. Marangoni's proposition that the plasticity of the saponaceous solution should be much superior to that of the distilled water, which is rather di. cult to admit owing to the peculiar rigidity of the surface of the former; incleed there are two totally different liquids in question; nevertheless, the author's statement seems to apply equally to both in this case.

In order to show that the laver of dirt can be accumulated upon one portion of the surface of a liquid and diminished upon another, II. Marangoni describes the the following curious experiment.

He plunges, into a soapy solution, a ring made of iron wire about seven and a half inches in diameter and fastened to the end of a fork which serves as a handle; when the ring is immersed he draw's it out again, holding it in a horizontal position; he then raises it until the catenoid wave, which unites it to the surface of the liquid, separates into two portions, one of which forms an even layer within the ring, while the other produces a spherical catity upon the liquid: now, if the temperature is low enough (from 12 to 14 degrees), this cavity is very holiow, the radius of the bise measuring 48 millimetres, while the height is only 27. M. Marangoni began this experiment four times, always breaking the cavity before again immersing the ring, and by this means he obtained the maximum of depression in which the depth was exactl; half of the radlus of the base. While the ring is being raised the circumference, in accordance with which the catenoid lamina unites with the surface of the liquid, contracts, and as M. Marangoni affirms, condenses the coating of dirt on the interior and lilates it on the exterior. Hence, when the cavity is once formed a diminution of tension takes place in the space limited by its base, and an increase of tension occurs on the outside this excess of tension consequently aids the basis of the cavity to enlarge, and results in the depth being diminished.

Ircorcling to my theory, the superficial layer of the liquid comtritets, as above stated, on the interior of the opening, and dilites on the exterior; but its consistency does not undergo any modification. The portion which contracts forces a part of its molecules into the mass b) $\because$ neath, and the dilated portions attract these atoms. Now, according to .II. Van der Mensbrugghe's theory which I hate mentioned already, these effects cannot be produced unless a diminution of tension takes place within the contracted portion and an augmentation of the same in the dilited part. This phenomenon, however, can only occur in a very low temperature, and when, in conseguence, the carities manifest a certain viscidity. When the temperature is notably higher the cavities are smaller and their depression less. At 26 degrees hardly any effect is visible. The radius of the base at this temperature was 23 millemetris, and the height 20 ; but I have shown that all cavities forned upon the surface of 
liquids are never complete hemispheres. M. Marangoni thinks it probable, as I have said before, that the coating of dirt on the saponaceous solution is due to the action of carbonic acid contained in the air.

I have ascertained that carbonic acid actually decomposes the solution inasmuch as it removes all fatty acicls; but does the formation of the layer really arise from this cause? In orcler to discover this the following experiment has been made:

A certain amount of a concentrated solution of caustic potash was placed within a bottle holding almost a quart, then, after tightly corking the latter it was vio!ently shaken so that the liquid swept over every part of the in. terior. 'The greater portion of the liquid was then poured out and the bottle instantly re-corked. In the meanwhile a funnel provided with a plug was procured and the interior of its neck moistened with the solution of potash; it was then placed in the neck of the bottle and wax applied at the: junction. This clone, almost 300 gramentes of a solution of Marscilles soap previously renderedi clear by means of filtration was poured into the funnel and left there for one hour. At the end of that time the wax was removed and the funnel gradually lifted, the plug being opened simultaneously, and, as the liquid flowed into the bottle the funnel continuetl to be slowly raised until the extremity of the reck was about on a line with the top of the bottle; the latter was then rapidly corked, some of the liquid remaining in the funnel.

The potash necessarily absorbed the small quantity of carbonic acid contained in the bottle, and at the moment when the funnel wats removed no exterior volume of air could possibly penetrate within the bottle, bectuse the stream of liquid llowing in must have expelled much more air thatl could pessibly have found its wit in toreplace the neck of the funin-l. Finally, as merely a portion of the liquid escaped into the bottle, ind that at a distatice far above the free surface. It could absorb nothing trion the superticial layer. Now, with this liquid merely united with air deprived of carbonic acid, transverse waves of a very persistent character were tasily d-veloped the bottle measured three and a quarter inches in diameteri, which could evidently not have occurred had the liquid b-en without an efficient coating. It is (quite impossible, therefore, for me to accept .I. Niarangoni's explanation. IB:sides, the effectual costing upon the saponaceous solution does not arise from the evaporation of watter; for a fatty liquid like soap-su(s, for instance, which proiluees bubbles in consequence of this consistency, does not eraporate at all, but, on the contrary, at!racis the dampness in the air. In order to assure myself that the effectual coating of the saponaceous sulution does not proceed from the evaporation of water as .I. Marangoni thinks it does, I added two parts of Price's glycerine to three parts of the solution, about the proportions generally used to produce a liquid glycerine, and the two substances were thoroughly mixed together. This compound, in conseguence of the glycerine, should absorb moisture instead of losing it now, by means of a pipe it produced bubbles at leitst two inches and a half in diameter. I then increased the quantity of glycerine, so that the two sulsstances were about equally divided, and eren then bubbles two inches in diameter were obtained. Thus, the effeclual coating of the solution is not due to the loss of water by evaporattion.

$\lambda$ s to the solution of albumen, inasmuch as its properties are analagous with those of the soapy solution, although less pronounced, I consir.cred it uscetess to make the same experiments in reference to it.

Now, if the cause which originates the formation of the effectual coaling upon the saponaceous solution is due neither to the action of carbonic acid contained in the air, nor to the evaporation of water, whence does it arise? Must we have recourse to Dupri's somewhat unacceptable ideil, which holds that in certain solu- tions the substance dissolved rises abundantly to the surface? Is it not much easier to admit, as I do, that the superficial coating of liquids forms itself sponta neously into a particular condition, which results in a greater or less difficulty in regarc to the relative displacement of the molecules than could occur in the interior of the mass? Does not the fact that tension exists suffice to show that this coating possesses an especial charicter in reference to the action of mole.ules?

The experiment which originated Dupre's singular idea mentioned above, is based upon the fact that the height of a tine stream of liquid precipitated from a certain distance must be considerably diminished by the tension of its surface, and Jupre, thereforc, concludes that in a little stream of soatp-suchs the tension is sensibly identical with that of pure water, while we all know that when a solution of soap is in a state of repose its tension cloes not approach that of water by two-thirds. Dupre concludes that in the strearn of sitionaceous solution. where the surface is constantly renewed, the soap itself has no opportunity of coming to the outside. But in my theory--it remarkable fact which 1 have myself contir.nel by an entirely different process which it is useless we refer to here-proves that the superficial coating of licpuids requires a certain amount of time, howeyer shost. (1) assume its proper atomical condition.

"But," says M. Maranguni, " the suferficial cuating of the saponaceous solution hats no extratordinary viscidity ; on the contrary, it is rery susceptible of motion." I acknowledge that it does in fict possess great mobility. which proceeds from the extrence thinness of its consistency. Mlso, it is capab!e in itself of making but slight resistance towards the movements of the magnetized nerdle. Still, as it arllures in its fullest citnacity to the underlying liguid, and should therefore attract a certain amount of the latter as it rotati:s, a irreater part of the resistance must necessarily be due in this fact. Moreover, we obserie, nothing goes to show us that the superticial latger, although very me bile, is le;s so than the underlying liquid if both are of an cqual consistency. We can reasonably admit this after an exferiment with the magnetized needle placed withi a the licpuid. Incleed, as the number of oscillations performed by MI Marangoni's ree-dle when in the l quid and when renooved from it were respectively tive 10 six, the governing powers of the needle in these two conditions are in proportion to the square of the above numbers, as, for instance, thirtysix to twenty-tive, or about thre to two. The resistance of the liquid robs the necelle of ne zrly one-third of its governing force; only as we require which part he two superficial coating's play in this resistance, nuthing prerents us from altributing it to the principal one of them.

Finall;, the resistince in regard to the displacing of molecul-s cannot be d-nied as far as the superticial layer of saponaceous solutuens is concerred, cons-quentiy we should admit this fact, although in a much less degree, in reference to solutions of soap itself. In one of $\mathrm{my}$ papers, and also in paragraph two hundred and severityeight of my book, 1 have described a certain number of lacts which prove the risclity existing in the effectual elerating of the saponaceous sr lution. I will cortine myself to cne of them as follows :

I bubble about an inch and a half in diamerer is blown and placed upon the surface of the liquid ; now, holding the mouth of the pip. in close contict with the he-misphere into which the bubste is transformed, you blow gently, increasing its dimensions untul it bursts. The spray inmediately spreads itself upon the liquirl in s'veral parts, cach, howeter, being separated from the surface be a small quantity of air. and gradually disaply ars as though sinking into the mass, the contraction occupving several seconds.'

.1. Marangoni, although maintaining perfect silence in

'In order t1" make this experiment successful, it $i$. llecessary to lise perfectly pure volution. 
regard to this powerful viscidity, relates several experiments which make the fact of its existence very perceptible. Let us quote the following which is merely the continuation of one I have already drawn altention to:

1 bubble is blown from a moderately wide tube which, however, has a broad mouth, and the other end is then left perfectly free. The bubble decreases gradually in si $\%$, but not in a perfectly systematic manner. On the contrary it elongates and at the same time contracts transversely, assuming a series of longritudinal folds or wrinkles. II. Mitrangoni explains this fact by stating that cwing to the diminution of the surfice, the couting of dirt becomes super siturated and consecpuenty the tension is anmulled or reiluced almost to nothing, inasmuch as th: thin lityer forming the bubble thus wrinkled and of at nearly conical shape does not show any tendency towards the minimum of the surface. But, he adds, if the unoccupied end of the tule should be conked so that the bubble would no: decrease in size, the form of the latterwould grow gradually round, and at the same time it would expel from the bottom certain drops of frosty muisture which forms in the little folds or wrinkles we have already mentioned; then the eoating of dirt would resume its normal condifion, and th: bubble assume, once more, a spherical shape.

.II. Marangoni supposes that apiat from the wrinkles on the bubble, the tension is utterly mull or very nearly so: Now, the existence of any liequid uteroly devorid of terision would he very extraurdinary and we maly sily hatrolly probsinle. Alereover, the drops of mossture in the interior of th: bubble, being the liguid which constitutes the outer coitting of dire, should possess little or no tension. I hatie cillected these drops upon the crystal of my watth, and aller repeating the experime it a number of times, I tinally procurad enough of the liquid to attempt the formanton of bubhles hy meaths of it. 11 must statte here that thes:

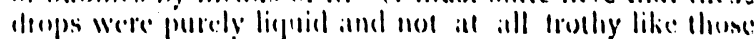
.11. Matrangent describes.) Now, bubhles were formed from this liguid, some of them extending three inchess in diameler, thit is to sit, they were similar in proportion (1) those obtained by means of the salponaceous solution: only; with the liquid collected from the drops in the crystil, this maximum was much more difficult to reach. In a word, I modified M. Marangoni's experiment in a manner calculated to render his explanation of it still more inprobable. I bubble about two inches in diameter was blown from the pipe and the drop suspended from the bottom remosed; hen, inasmuch as the tulse wiss expressly natrow, the wrinkled and cone shaped form was produced by inhaling through it. and hefore the (Irop) produced at the extreme poine of the conc could fall, the pipe was turned upside down in such a way that the liquid forming the drop ran along the surface of the bubble and separated itself as much as possible on the exterior. Now, although the superficial coating thus conserves very nearly its former consistency, and as conn. seyuently (accor!ling lo M. Marangeni), the tension be-

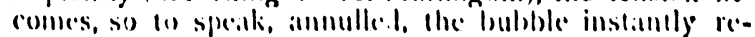

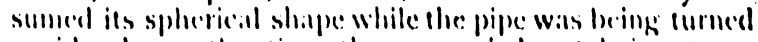
upside: down, the time lhus occupied not beinge mose than one second. This expreriment wats leperaterel s:veral time's and alwatys with the sitme result.

In my opinion these facts cian be explained very simply: When you breathe through the pipas, should it be moderately wide or even narrow, the bubble necessarily contracts. It consequently becomes of a thicker consistency and a surplus amount of liquld flows towards the lower extremity; but the strong viscidity of the superficial coatings renders the generil augmentation of density, and the egual centraction on all sicles. very difficult during the short interval of reduction. The surface wrinkles in very much such a manner as a small bladder would should the air within it be inhaled, and at the same time it elongates into a conical form from the weight of the liquid which accumulates at the bottom. Fevertheless, this liquid arising from the increased density of the bubble does not notably diminish the tension, as is shown by the fact that when the pipe is held upside down and the liquid rests upon the bubble sitelf, the latter regains its spherical form immediately.

In regrard to the superticial conting of the solution of sualp. M. Marangoni observed that if this coating was viscous it should wrinkle when before the needle, which, however, does not occur at all. In order to discover what really takes place in reference to this circumstance, I began the experiment once more by sprinkling the surface of the solution with pollen' just before liberating the necdle. If allention is then drawn to the tension of the needle, it will be see'l that on the side toward which this half advonces, and cuntel a moderate distance is reached, the dispersion of the pollen is diminished, while on the epposite side--that is to s av, behind the particular hall--it is considerably increased. Thus, the superticial coitting in front of the needle, instead of puckering. contracts, and dilates behind it. Now, if we reason in accordance with iny theory, and consequently do not admit the existence of a coating of dirt, we should acknowledge that in the portion constructed the molecules per. taining to the superficial coating have lett it and entered the interior of the mass, and also that in the dilated portion the molecules belonging to the interior have annexed themselves to the sup): ricial costun : in order to maintain the density; thess two effects could not be produced, moreoser, unless a certain ambunt of resistance existed. They have necessatrily developed also a diflerence of tension: but, ia the second of the two series of estimates which I eflected in reference (o) the durition of the meedle's moverments on the surfice and in the interior of the solution, the temperilure wals about 21 ", and from M. Mallangoni's observaltons upon the spherical cavities before ill -ntioned, it follows that at this degree of temperatture he differences of lension should posse'ss but slight

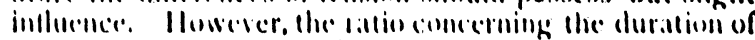

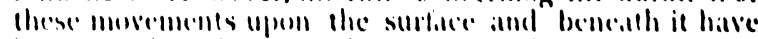
been foumel to about eyual 1--78. Besieles, these experiments seemed to tesult in showing thatt the eflect arising from the ditferellee of tension is not altogether to be overlooked, for in the first series in question when the temperature was but 18 , the ratio of duration was somewhat increased; that is to say, about $1-87$.

It the beginning of these remarks it was seen that $\mathrm{M}$. Matrangroni explains the retardeal motion of the needle upon the solution of soilp by the difference existing betwe'th the tension of the dirty coatting and that of the lieguid benciath. We hate alse seen that in regiard to liguids such at witler, sillime solutions, ctle. which also retand the needle's movements, he seemed somewhat embarratssed. At the commencement of his work, he insists upon the capillary action of the meniscus, then further on, he appears to attich but little importance to it, and inrokes a small quantity of dirt; further on still, he takes refuge in .I. Van der Mensbrugghe's theory.

Is far as the capillary action of the meniscus is con-

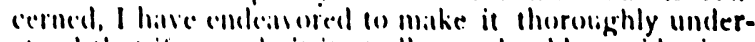
stomel that if we anlmit it all ill, We should consieler it as being probshble the very reverse of What M. Matrangoni stlpposeses. He knows, moreover, that the action of a meniscus would not be sulliciene in itself 10 sittisfactorily explain the exist:nce of any phenomena ; for example. it could not acesunt for the rotation of the entire surface of the liquicl. M. Marangoni, therefore, only ascribes a partial rilc to it, and at the same time secks protection uncler a conting of dirt and the ideas expressed by $M$. Van der Mensbrugghe. But, you will ask, where then does this coating of dirt come from : Does it arise from particles of dust floating about in the atmosphere? In his tirst Work M. Marangoni says that water which has

'In order to do this, the pollen must be spread upon the surface of the liyuid hy me:ans of a small paper tule lield at a certan distance above the solution. Care muit be tiaken to do this as yuickly as possible, as the soap 
been distilled several times can remain exposed to the air for six or eight days without the slightest augmentation of resistance, in regard to the needle, being apparent. Besides. in the measures taken with distilled water, the entire preparation of the experiment from the moment when the liquid was poured into the capsule until the needle, was left to itself, occupied but five ministes; then during the ten partial measures afterward effected, no increase of resistance was observable. Could narticles of dust floating about in the atmosphere produce an effect during those five minutes? Is it admissible? Indeed. M. Hagen has shown us conclusitely that the superficial tension of distilled water decreases purceptibly when the liquid is exposed to the air : but this diminutinn is gradual and continued, and in order to prodluce any visible effect req'ires several hours The peculiar fact $M$. Hagen describes, therefore, appears to me to bear no relation whatever to the resistance shown to the needle's movements; and inasmuch as air on the other hani. exercises no chemical action upon distilled water, and morrover as we are unable to invoke the influence of particles of atmospherical dust, we are led to attrihute the fact established by M. Uagen to a cause arising from the interior of the liquid.

Now, in reference to the actual state of the case, I shall say again that it is useless to have recnurse to a coating of dirt whose existence we cannot account for. and also that it is much more simple to admit the presence of an atomic organization peculiar to the superficial layer of the liquid.

As far as M. Van der Mensbrugghe's theory is concerned, M. Marangoni expresses himself in the following manner:

"The mass of the liquid effectually diminishes the variations of temperature produced upon the surface, which. in its turn, also decreases the variations of tension ; in ordinary cases the latter are but trifling when compared with the variations attributed to dirt."

According to this remark; we should believe that the surface of the saponaceous solution, which, M. Marangoni states, possesses an undeniable coating of dirt, resists the movements of the needle more forcibly than the distilled water which could have hardly anv dirt on its surface. In my experiments however. directly the opposite of this has occurred. The ratio of time required for the needle to describe an angle on the surface and beneath it when distilled water was used was, 1, 92, while when soan was used it was but 1.82.

M. Van der Mengsbrugge's theory certainly deserves some attention in regard to the phenomena in question: hut owing to the above remark of M. Marangoni, and the considerable dimension of the nerdle, relatively speaking, we may be permitted to doubt that any notable effect can result from it. Besides, if it diil, we should find it again in those liquids of weak tersion which do not produce bubbles, that is to sity, alcohol, spirits of turpentine, olive oil, etc.; at leist we should be able in observe a feeble rotation of the entire surface: now, this is by no means authenticited.

Finally, before attributing these phenomena io any other cause than that of a peculiar viscidity of the outer coating, it would be necessary to refute those arguments which have led me to the conclusion that the superficial coating of liquids possesses more atomic mobility than the interior nortion. M. Marangeni is perfectly silent in regard to this part of my work.

After this examination of M. Marangoni's theory however, I consider my celf justified in maintianing my opinion; but I forego all ulterior discussions referrme to the suldject, and leave all those physicists who maly he interested in the question, to compare for themselies M. Marangoni's writings with mine, and to try 10 discover, if possible, which of us is right.

\section{ON THE STRUCTURE OF THE ORANG DUTANG.}

By He.nry C. Cuapman, M. D.

From the paper on this suhject in the Proceedings of the Acartemy of $N$ itural Sciences, of Philadelphia. we take the following facts:

The subject dissected was a young in ale Orang Outang (Simia Satyrus), about three years old. The first thing to strike Dr. Chapman was the length of the upper extremity, it being three inches longer than the lower one, agreeing nearly in this respect with the forilla, the difference in the extremities of that animal being $3 \frac{1}{2}$ inches, whereas in the Chimpanzee a difference of 13 inches onlv was found. The foot in the Orang, howevrr, was $1 / 2$ inch larger than the hand, wher=as in the Gorilla the hand was $1 / 2$ inch larger than the font; in the Chimpanzee the difference in this respect was $;$; in. in favor of the font. Inderd, the dis'inctness of hand and fort superficially is more marked in the Corilla than in the other anthropoids. The same facial muscles are found in man and the Orang Outang, with the exception that there is but one zygoma. ticus, possibly corresponding to the eygomaticus minor of mon. The facial muscles, however, are not differentiated as in man, rathrr hanging together. The upper extremity of the Orang, in its muscles, differed essentiallyfrom that of man in the absence of the flexor longus p lllicis, and extensor primi internodii pollicis and in the prest.oce of the additional tendons to th- rine and iniddle fingers."

The Orang agreed with the Gorilla in not having a flexnr longus pollicis, but disagreed with it in having the promator radii teres, arising by two heads in the presence of a palmaris longus, in the cilditional tendons for ring and middle fingers, and in not hating the extensor primi internodii pollicis.

Is compared with the Chimpanace, the Orang agreed in reference to the pronitor rudii teres and palmaris longus, but in the absence of the flrxor longus pollicis as a slip irom the profundus, and in the presence of the aclditional extensor tendons it differed.

Dr. Chapman differed from Bischoff. Owen, Huxley and others, in seeing no essential difference between the scansorius, of Traill, and the glutitus minimus in man, an opinion, it appears, which had been previously expressed by Prof. Barnard in 1876 .

The ling and the foot of the Orang, as compared with man, differed in the absence of the peroneus tertius, plantaris, flexor longus hallucis and transversus pedis, in the fibular origin of the soleus, and in the presence of the external origin of the accessorius only. in the distribution of the perforating and perforated tendons of the toes, in the interossei, and in the presence of an opponens for the big toe. In this latter respect, the Orang differs not only from man, but from all the other monkeys and anthropoids, the foot having a very hand-like appearance, as compared with that of the ciorilla and chimpanzere. The foot of the ()rang differs further in the absence of a special flexor for the big toe. This is supplementerl, to a certain extent, by the opponens, and in a partly developed accessorius.

If Professor lluxley's canon c.m be accepted that the distinction between a hand and a fout consists in the latter possessing tarsal bones, the peroneus longus and brevis, the short extensor and short flexor muscles, then the posterior extremity of the (Orang terminates in a fuot.

Dr. Chapman, however, appeared to think that the difference bedween the haml and the foot in .Man. the Gurilla, and Chimpandere, and the lower monteys, is greater than that observed between the corresponding members of the Oritng.

It is usually stilled that the uviula is absent in the Orangy, and on looking into the mouth, at lirst sight this appears to be the caser, as it doe's not hang down as in man, between the pillars of the fauces. Neveriheless, Dr. Chap- 